\title{
A light on the dark side: in vivo endoscopic anatomy of the posterior third ventricle and its variations in hydrocephalus
}

\author{
*Alberto Feletti, MD, PhD, ,, Alessandro Fiorindi, MD, PhD, ,,4 Vincenzo Lavecchia, MD, ${ }^{2}$ \\ Rafael Boscolo-Berto, MD, ${ }^{5}$ Elisabetta Marton, MD, ${ }^{4}$ Veronica Macchi, MD, PhD, ${ }^{5}$ \\ Raffaele De Caro, MD, ${ }^{5}$ Pierluigi Longatti, MD, ${ }^{4}$ Andrea Porzionato, MD, PhD, ${ }^{5}$ and \\ Giacomo Pavesi, MD2
}

\begin{abstract}
'Department of Neurosciences, Biomedicine, and Movement Sciences, Institute of Neurosurgery, University of Verona; 2Department of Neurosciences, Neurosurgical Unit, University of Modena; ${ }^{3}$ Neurosurgical Department, Spedali Civili, University of Brescia; ${ }^{4}$ Neurosurgical Department, Treviso Regional Hospital, University of Padova, Treviso; and ${ }^{5}$ Department of Neuroscience, Institute of Human Anatomy, University of Padova, Italy
\end{abstract}

OBJECTIVE Despite the technological advancements of neurosurgery, the posterior part of the third ventricle has always been the "dark side" of the ventricle. However, flexible endoscopy offers the opportunity for a direct, in vivo inspection and detailed description of the posterior third ventricle in physiological and pathological conditions. The purposes of this study were to describe the posterior wall of the third ventricle, detailing its normal anatomy and surgical landmarks, and to assess the effect of chronic hydrocephalus on the anatomy of this hidden region.

METHODS The authors reviewed the video recordings of 59 in vivo endoscopic explorations of the posterior third ventricle to describe every identifiable anatomical landmark. Patients were divided into 2 groups based on the absence or presence of a chronic dilation of the third ventricle. The first group provided the basis for the description of normal anatomy.

RESULTS The following anatomical structures were identified in all cases: adytum of the cerebral aqueduct, posterior commissure, pineal recess, habenular commissure, and suprapineal recess. Comparing the 2 groups of patients, the authors were able to detect significant variations in the shape of the adytum of the cerebral aqueduct and in the thickness of the habenular and posterior commissures. Exploration with sodium fluorescein excluded the presence of any fluorescent area in the posterior third ventricle, other than the subependymal vascular network.

CONCLUSIONS The use of a flexible scope allows the complete inspection of the posterior third ventricle. The anatomical variations caused by chronic hydrocephalus might be clinically relevant, in light of the commissure functions.

https://thejns.org/doi/abs/10.3171/2020.4.JNS20493

KEYWORDS anatomy; posterior commissure; habenular commissure; hydrocephalus; neuroendoscopy; pineal gland; third ventricle

$\mathrm{T}$ HE third ventricle is among the most surgically inaccessible areas in the brain. In particular, its posterior part poses a challenge for neurosurgeons. The most common route to reach lesions in this area is from a posterior supracerebellar infratentorial approach to the quadrigeminal cistern. The anatomy of the so-called "pineal region" has been widely described from this point of view. ${ }^{1}$ However, with the technological development of neuroendoscopic tools, the approach from inside the third ventricle through a trans-Monro foramen route has become widely used. Despite numerous reports of endoscopic approaches to the posterior part of the third ventricle to perform biopsies or partial or total removal of tumors involving the pineal region and the aqueduct, or to fenestrate quadrigeminal cysts, there is a lack of information about the in vivo anatomy of the posterior wall of the third ventricle. The aim of this study was to review cases of endoscopic exploration of the posterior wall of the third ventricle of

ABBREVIATIONS IVH = intraventricular hemorrhage; SCO = subcommissural organ

SUBMITTED February 16, 2020. ACCEPTED April 15, 2020.

INCLUDE WHEN CITING Published online July 3, 2020; DOI: 10.3171/2020.4.JNS20493.

* A. Fiorindi and V.L. contributed equally to this work, and A.P. and G.P. contributed equally to this work. 
patients with and without triventricular or tetraventricular hydrocephalus, describe the normal endoscopic anatomy of the pineal region, and compare it with the anatomy in cases of ventricular chronic dilation.

\section{Methods}

From January 2015 to April 2019, 171 intraventricular neuroendoscopic procedures were performed at our institutions. All patients gave informed consent, which was approved by the institutional board. We reviewed all video recordings of the operations and selected the cases of patients affected by triventricular hydrocephalus due to aqueductal stenosis or neoplastic obstruction of the caudal aqueduct, monoventricular and biventricular hydrocephalus due to a colloid cyst, tumors of the foramen of Monro, atresia of the foramina of Monro, tetraventricular hydrocephalus, or intraventricular hemorrhage (IVH). All cases of tumors growing in the posterior part of the third ventricle were excluded, as were those with missed or unclear intraoperative images. A total of 59 patients (21 patients with IVH, 31 patients with triventricular and tetraventricular hydrocephalus, and 7 patients with mono- or biventricular hydrocephalus) were included in the study. We reviewed all selected cases, retrieving data from our neuroendoscopic clinical and video databases.

In all cases, a flexible endoscope was used (Karl Storz $\mathrm{GmbH} \& \mathrm{Co}$; external diameter $3.7 \mathrm{~mm}$, operative channel diameter $1.5 \mathrm{~mm}$ ), connected to an Image $1 \mathrm{H} 3-\mathrm{Z}-\mathrm{FI}$ Spies camera (Karl Storz GmbH \& Co.). The scope was equipped with dual observation modalities for white light and fluorescence through a dedicated double filter (D-light AF system C, Karl Storz GmbH \& Co.). The images were projected on a 26-inch monitor HD (Karl Storz GmbH \& Co.).

The patients were classified into 2 groups based on the presence of a chronically dilated third ventricle. We assumed patients with mono- and biventricular hydrocephalus and patients with IVH to have a normal third ventricle anatomy, compared with patients with chronic dilation of the third ventricle.

The shape of the adytum of the cerebral aqueduct, the thickness of the posterior and habenular commissures, and the shape of the pineal recess were directly visually assessed and cataloged for both groups. In selected cases, $8-10 \mathrm{mg} / \mathrm{kg}$ sodium fluorescein was intravenously administered, and the anatomical structures were visualized through a blue light filter to highlight subependymal vessels and any area lacking the blood-brain barrier, both physiological (some circumventricular organs) and pathological (tumors and phlogosis). ${ }^{2}$

\section{Statistical Analysis}

For the continuous variable (age), mean and standard deviation were used to describe the parametric variables. Accordingly, the Student t-test was used for comparison between subgroups. Relationships between categorical variables were assessed by chi-square test. For all analyses, a two-sided $\mathrm{p}<0.05$ was taken to indicate statistical significance.

\section{Technical Endoscopic Aspects and Precautions During Navigation of the Posterior Third Ventricle}

When inserting the flexible scope through the peelaway introducer into the right lateral ventricle, usually the Monro foramen is immediately faced. The choroid plexus is shown at the bottom of the screen, the thalamostriate vein appears at the bottom right, the septum pellucidum stands at the left, and the column of the fornix outlines the anterior part of the Monro foramen. The scope is then advanced through the foramen of Monro to enter the third ventricle (Fig. 1). The mammillary bodies and the tuber cinereum are the first visible structures. At this stage, the tip of the scope must be bent backward as it is further advanced along the floor of the third ventricle. It is important for the tip of the scope to be quite close to the mammillary bodies before tilting it to avoid hitting the posterior edge of the foramen of Monro where the choroid plexus and the internal cerebral vein start their course along the roof of the third ventricle. The floor of the third ventricle will therefore be visible at the top of the screen, while the adhaesio interthalamica appears at the bottom and is then passed after the scope is moved below it toward the posterior third of the third ventricle. In this region, the following anatomical structures are visualized on the screen from top to bottom: the adytum of the cerebral aqueduct, the posterior commissure, the pineal recess, the habenular commissure, the suprapineal recess, the roof of the third ventricle covered by choroid plexus, and the internal cerebral veins (Fig. 2).

Although the scope is deeply advanced into the third ventricle, as long as the movements are careful and smooth, the ependyma cannot be damaged, even at the narrowest passage of the foramen of Monro, as the scope is flexible and nicely adapts to the irregular, complex shape of the ventricular system sliding through it.

\section{Neuroanatomical Study on Postmortem Samples}

The posterior third ventricle was also analyzed in 3 postmortem brains, sampled from cadavers ( 2 females, 30 and 67 years old; 1 male, 70 years old) from the Body Donation Program of the University of Padua. ${ }^{3}$ The brains were fixed in $10 \%$ formalin for 30 days. The brainstem and cerebellum were removed through the transverse section at the level of the superior colliculi. The third ventricle was sampled en bloc through 2 paramedian sagittal sections passing laterally to the epiphysis and through corpus callosum, thalamus, and hypothalamus. The sample was then paraffin embedded and serially sectioned from one side to the other. Every tenth section was stained with $\mathrm{H} \& \mathrm{E}$ and analyzed with particular reference to the posterior third ventricle. The topographical distribution of the choroid plexus was also considered, both macro- and microscopically.

\section{Results}

The anatomical observations obtained in the 2 groups of patients are listed in Table 1. Table 2 shows the summary of the anatomical variations observed in the posterior third ventricle. There were no statistically significant differences between the dilated ventricle and normal anatomy 


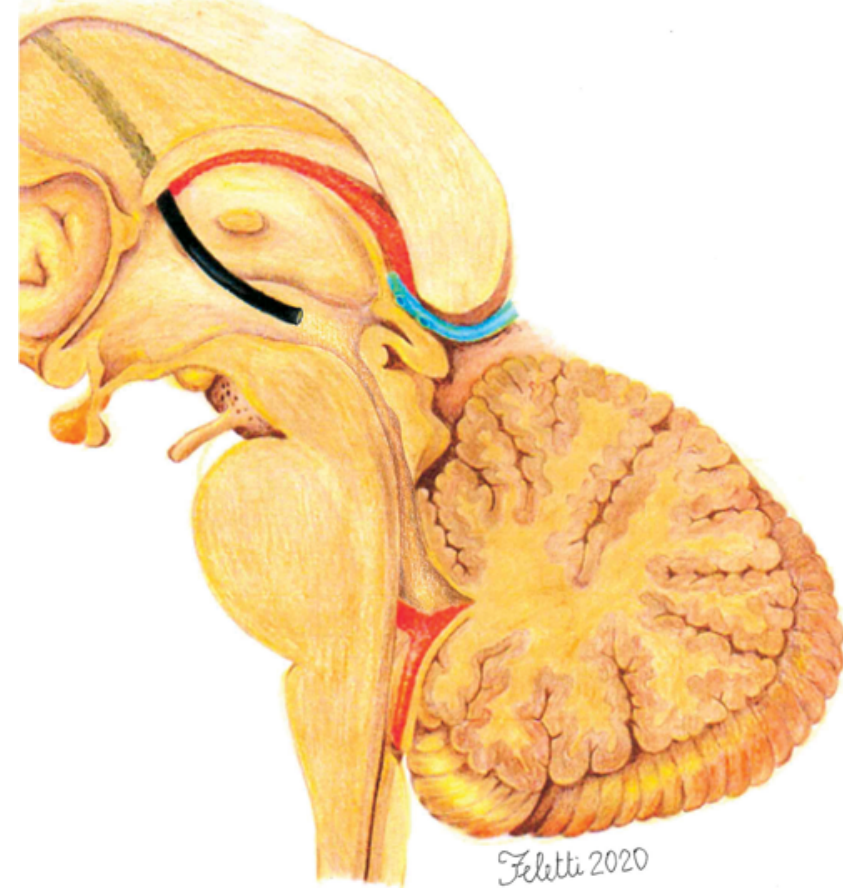

FIG. 1. Artist's illustration showing the path of the endoscope (black curved line) through the foramen of Monro into the third ventricle. The tip of the scope is bent backward and advanced below the adhaesio interthalamica to inspect the posterior part of the third ventricle. Copyright Alberto Feletti. Published with permission.

groups for sex distribution (M/F $12 / 19$ and $16 / 12$, respectively; $\mathrm{p}=0.25)$ or age $(51.6 \pm 21.6$ vs $60 \pm 15.3$ years, respectively; $\mathrm{p}=0.09$ ).

Comparing the groups of patients, we found that a rounded or stenotic shape of the adytum of the cerebral aqueduct was more often encountered in the dilated ventricle group $(\mathrm{p}<0.01)$. None of the patients presenting with IVH showed a stenotic adytum.

While the posterior and the habenular commissures usually appear thick in normal anatomy, they become thin in a significant number of patients with chronic hydrocephalus ( $p<0.01$ for posterior commissure, $p<0.01$ for habenular commissure; Fig. 3 and Videos 1 and 2).

VIDEO 1. Patient 28. Anatomy of the posterior third ventricle in a case of chronic hydrocephalus. The adytum of the cerebral aqueduct is rounded and oval-shaped, due to membranous obstruction of the caudal part of the aqueduct. Both the posterior and the habenular commissures appear thin, and the pineal recess is slit. Copyright Alberto Feletti. Published with permission. Click here to view.

VIDEO 2. Patient 46. Anatomy of the posterior third ventricle in a case of acute IVH. The adytum of the cerebral aqueduct is triangular, shaped by the posterior commissure posteriorly and the rubral nuclei anteriorly. Both the posterior and the habenular commissures are thick, and the pineal recess is open. Copyright Alberto Feletti. Published with permission. Click here to view.

No significant difference was detected in the shape of the pineal recess comparing the 2 groups $(\mathrm{p}=0.14)$.

Interestingly, in the majority of cases with normal anatomical features, a yellowish choroid plexus partially covers the habenular commissure. Conversely, in cases of
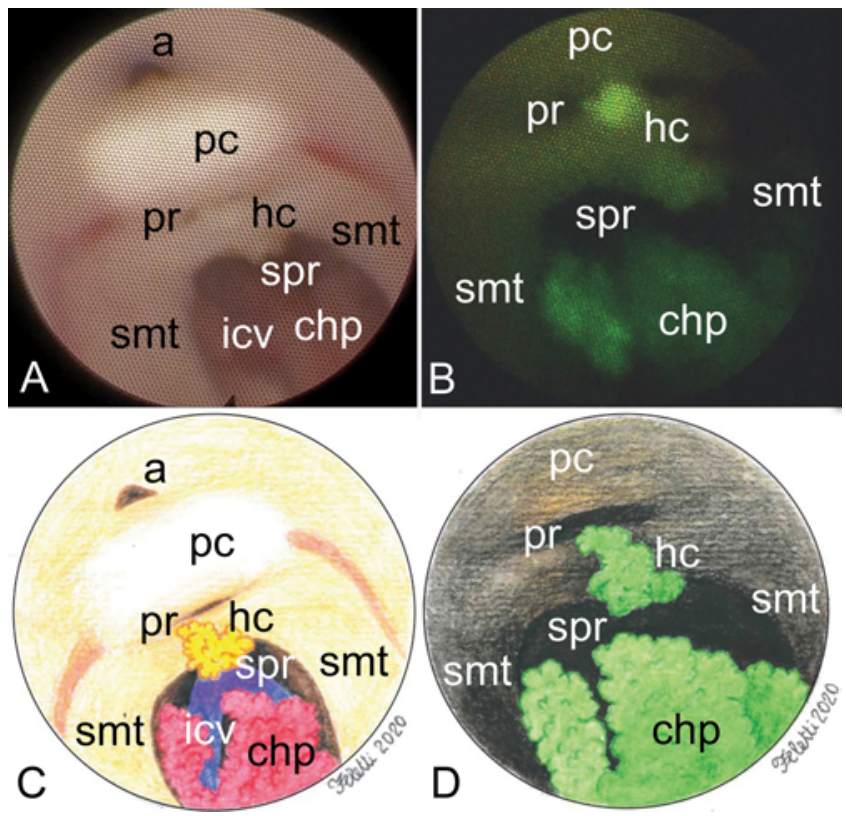

FIG. 2. Endoscopic anatomy of the posterior third ventricle. A: White light inspection revealing the adytum of the cerebral aqueduct, posterior commissure, pineal recess, habenular commissure, stria medullaris thalami, suprapineal recess, roof of the third ventricle covered by choroid plexus, and the internal cerebral veins. B: Closer vision after sodium fluorescein intravenous injection. Compared with panel $A$, the tip of the endoscope is a bit closer to the roof of the third ventricle in order to make fluorescence more evident on the black background. Only the choroid plexus is highlighted, both on the roof of the third ventricle and on the habenular commissure. The stria medullaris thalami, posterior commissure, and habenular commissure are not fluorescent, while the suprapineal recess and the pineal recess appear black. C and D: Artist's illustrations showing the posterior third ventricle with white light $(C)$ and fluorescence mode (D). a = adytum of the cerebral aqueduct; $\operatorname{chp}=$ choroid plexus; $\mathrm{hc}=$ habenular commissure; icv = internal cerebral vein; $\mathrm{pc}=$ posterior commissure; $\mathrm{pr}=$ pineal recess; $\mathrm{smt}=$ stria medullaris thalami; spr = suprapineal recess. . Copyright Alberto Feletti. Published with permission.

chronic hydrocephalus, this yellowish choroid plexus is frequently absent ( $p=0.02$; Fig. 4). Exploration with sodium fluorescein excluded the presence of any fluorescent area in the posterior third ventricle, except for the subependymal vascular network and choroid plexus (Fig. 2).

Analysis of the third ventricle in macroscopic sagittal sections showed that the main body of the choroid plexus was located along the ventricular roof, as usually described in anatomical atlases, but a small portion of the choroid plexus can extend inferiorly and posteriorly in front of the habenular commissure (Fig. 5).

The pineal gland was clearly visible on the posterior aspect of the third ventricle (Fig. 6). In all cases it showed numerous calcified concretions. The profile of the pineal recess was very thin and clearly recognizable only at the level of the pineal stalk, between the habenular and posterior commissures, and not in the main body of the gland. The pineal gland did not show microvascular organization typical of other circumventricular organs such as the area postrema. ${ }^{4}$

The posterior commissure was characterized by an 
TABLE 1. Patient demographics and anatomical features

\begin{tabular}{|c|c|c|c|c|c|c|c|c|}
\hline Patient No. & $\begin{array}{l}\text { Age } \\
\text { (yrs), } \\
\text { Sex }\end{array}$ & Disease & Procedure & $\begin{array}{c}\text { Adytum of the } \\
\text { Aqueduct }\end{array}$ & PC & $\mathrm{HC}$ & $\begin{array}{c}\text { Choroidal } \\
\text { Plexus on } \\
\text { HC }\end{array}$ & $\begin{array}{l}\text { Pineal } \\
\text { Recess }\end{array}$ \\
\hline \multicolumn{9}{|c|}{ Dilated 3rd ventricle } \\
\hline 1 & $65, \mathrm{~F}$ & ACPF & ETV, fenestration of ACPF & Rounded & Thin & Thin & Yes & Slit \\
\hline 2 & $37, \mathrm{M}$ & AS & ETV & Stenotic & Thick & Thin & Yes & Wide \\
\hline 3 & $43, F$ & $\mathrm{CHB}$ & $\begin{array}{l}\mathrm{AQP}+\text { stent, fenestration of } \mathrm{CHB} \text {, left Lushcka- } \\
\text { plasty }\end{array}$ & Rounded & Thin & Thin & Yes & Slit \\
\hline 4 & $49, \mathrm{~F}$ & FVOO & ETV & Triangular & Thick & Thick & Yes & Slit \\
\hline 5 & $33, \mathrm{~F}$ & AS & ETV & Rounded & Thin & Thick & No & Slit \\
\hline 6 & $78, \mathrm{~F}$ & AS & ETV & Rounded & Thin & Thin & No & Wide \\
\hline 7 & $64, \mathrm{~F}$ & AS & $\mathrm{ETV}+\mathrm{AQP}$ & Stenotic & Thick & Thin & No & Wide \\
\hline 8 & $77, \mathrm{M}$ & AS & ETV & Stenotic & Thick & Thick & Yes & Slit \\
\hline 9 & $66, M$ & AS & ETV & Rounded & Thin & Thin & No & Wide \\
\hline 10 & $50, M$ & AS & ETV & Rounded & Thin & Thin & No & Slit \\
\hline 11 & $15, M$ & AT & ETV & Stenotic & Thick & Thin & No & Wide \\
\hline 12 & $67, \mathrm{M}$ & $A C Q C$ & AQP & Triangular & Thin & Thin & Yes & Wide \\
\hline 13 & $19, F$ & AS & ETV & Rounded & Thick & Thin & No & Slit \\
\hline 14 & $51, \mathrm{M}$ & FVOO & ETV & Triangular & Thick & Thick & Yes & Slit \\
\hline 15 & $73, \mathrm{M}$ & AS & AQP & Rounded & Thin & Thin & Yes & Wide \\
\hline 16 & $47, \mathrm{~F}$ & PFT & ETV & Triangular & Thick & Thick & Yes & Wide \\
\hline 17 & $63, F$ & AS & ETV & Stenotic & Thin & Thin & No & Slit \\
\hline 18 & $9, \mathrm{~F}$ & PFT & ETV & Triangular & Thick & Thin & No & Slit \\
\hline 19 & $35, F$ & AS & ETV & Rounded & Thin & Thin & Yes & Slit \\
\hline 20 & $73, \mathrm{~F}$ & Lymph & Biopsy & Rounded & Thin & Thin & Yes & Wide \\
\hline 21 & $57, \mathrm{~F}$ & ACPF & ETV & Rounded & Thick & Thick & No & Slit \\
\hline 22 & $73, \mathrm{M}$ & HIT & Biopsy & Triangular & Thick & Thin & Yes & Slit \\
\hline 23 & $65, M$ & AS & ETV & Rounded & Thin & Thin & Yes & Slit \\
\hline 24 & $66, F$ & AT & ETV & Stenotic & Thick & Thick & No & Wide \\
\hline 25 & $83, \mathrm{M}$ & PFT & ETV & Rounded & Thin & Thin & Yes & Slit \\
\hline 26 & $25, \mathrm{~F}$ & FVOO & ETV & Stenotic & Thick & Thin & No & Wide \\
\hline 27 & $58, F$ & $\mathrm{NPH}$ & ETV & Triangular & Thick & Thin & Yes & Wide \\
\hline 28 & $26, F$ & AS & AQP & Rounded & Thin & Thin & Yes & Slit \\
\hline 29 & $47, \mathrm{~F}$ & AS & ETV & Triangular & Thick & Thin & No & Slit \\
\hline 30 & $70, F$ & AS & ETV & Rounded & Thick & Thin & No & Wide \\
\hline 31 & $65, M$ & AS & ETV, AQP & Rounded & Thin & Thin & Yes & Wide \\
\hline \multicolumn{9}{|l|}{ Normal anatomy } \\
\hline 32 & $3, M$ & LVPP & Inspection & Triangular & Thick & Thin & No & Slit \\
\hline 33 & $35, \mathrm{M}$ & IVH & Aspiration & Triangular & Thick & Thick & No & Wide \\
\hline 34 & $79, \mathrm{M}$ & IVH & Aspiration & Rounded & Thick & Thin & Yes & Wide \\
\hline 35 & $49, \mathrm{M}$ & IVH & Aspiration & Triangular & Thick & Thick & Yes & Wide \\
\hline 36 & $55, \mathrm{~F}$ & IVH & Aspiration & Triangular & Thick & Thick & Yes & Slit \\
\hline 37 & $32, \mathrm{~F}$ & IVH & Aspiration & Triangular & Thick & Thick & No & Wide \\
\hline 38 & $43, \mathrm{M}$ & IVH & Aspiration & Triangular & Thick & Thick & Yes & Wide \\
\hline 39 & $81, \mathrm{~F}$ & $\mathrm{IVH}$ & Aspiration & Triangular & Thin & Thin & Yes & Wide \\
\hline 40 & $61, \mathrm{M}$ & IVH & Aspiration & Rounded & Thick & Thick & Yes & Slit \\
\hline 41 & $47, \mathrm{~F}$ & IVH & Aspiration & Triangular & Thick & Thick & Yes & Wide \\
\hline 42 & $78, \mathrm{M}$ & $\mathrm{IVH}$ & Aspiration & Rounded & Thick & Thick & Yes & Wide \\
\hline 43 & $74, \mathrm{M}$ & $\mathrm{IVH}$ & Aspiration & Rounded & Thick & Thin & Yes & Wide \\
\hline 44 & $52, \mathrm{~F}$ & IVH & Aspiration & Rounded & Thick & Thick & No & Slit \\
\hline
\end{tabular}




\begin{tabular}{|c|c|c|c|c|c|c|c|c|}
\hline Patient No. & $\begin{array}{c}\text { Age } \\
\text { (yrs), } \\
\text { Sex }\end{array}$ & Disease & Procedure & $\begin{array}{c}\text { Adytum of the } \\
\text { Aqueduct }\end{array}$ & PC & $\mathrm{HC}$ & $\begin{array}{c}\text { Choroidal } \\
\text { Plexus on } \\
\text { HC }\end{array}$ & $\begin{array}{l}\text { Pineal } \\
\text { Recess }\end{array}$ \\
\hline \multicolumn{9}{|c|}{ Normal anatomy (continued) } \\
\hline 45 & $61, M$ & IVH & Aspiration & Triangular & Thick & Thick & Yes & Slit \\
\hline 46 & $54, \mathrm{M}$ & IVH & Aspiration & Triangular & Thick & Thick & Yes & Wide \\
\hline 47 & $63, M$ & IVH & Aspiration & Rounded & Thick & Thick & No & Wide \\
\hline 48 & $76, \mathrm{M}$ & IVH & Aspiration & Rounded & Thick & Thick & Yes & Slit \\
\hline 49 & $73, \mathrm{~F}$ & IVH & Aspiration & Triangular & Thick & Thick & No & Wide \\
\hline 50 & $71, \mathrm{~F}$ & IVH & Aspiration & Triangular & Thick & Thick & Yes & Slit \\
\hline 51 & $76, \mathrm{M}$ & IVH & Aspiration & Rounded & Thick & Thin & Yes & Slit \\
\hline 52 & $76, \mathrm{M}$ & IVH & Aspiration & Triangular & Thick & Thick & Yes & Wide \\
\hline 53 & $66, M$ & IVH & Aspiration & Triangular & Thick & Thick & Yes & Wide \\
\hline 54 & $45, M$ & $\mathrm{CC}$ & Removal & Triangular & Thick & Thin & Yes & Slit \\
\hline 55 & $37, \mathrm{~F}$ & MA & Monroplasty & Triangular & Thick & Thick & Yes & Slit \\
\hline 56 & $47, \mathrm{~F}$ & MS & Subtotal removal, Monroplasty & Triangular & Thick & Thick & Yes & Wide \\
\hline 57 & $44, \mathrm{~F}$ & $\mathrm{CC}$ & Removal & Triangular & Thick & Thin & Yes & Wide \\
\hline 58 & $67, \mathrm{~F}$ & $\mathrm{CC}$ & Removal & Triangular & Thick & Thin & Yes & Slit \\
\hline 59 & $78, \mathrm{~F}$ & $\mathrm{CP}$ & Fenestration of cyst & Triangular & Thick & Thin & Yes & Wide \\
\hline
\end{tabular}

$\mathrm{ACPF}=$ arachnoid cyst in the posterior fossa; $\mathrm{ACQC}=$ arachnoid cyst of the quadrigeminal cistern; $\mathrm{AQP}=$ aqueductoplasty; $\mathrm{AS}=$ aqueductal stenosis; $\mathrm{AT}=$ aqueductal tumor; $\mathrm{CC}=$ colloid cyst; $\mathrm{CHB}=$ cystic hemangioblastoma of the obex; $\mathrm{CP}=$ craniopharyngioma; $\mathrm{ETV}=$ endoscopic third ventriculostomy; $\mathrm{FVOO}=$ fourth ventricular outlet obstruction; $\mathrm{HC}=$ habenular commissure; HIT = hypothalamic-infundibular tumor; LVPP = plexus papilloma of the lateral ventricle; lymph = lymphoma; MA = atresia of the foramen of Monro; MS = subependymoma of the foramen of Monro; NPH = normal pressure hydrocephalus; $\mathrm{PC}=$ posterior commissure; $\mathrm{PFT}=$ posterior fossa tumor.

external posterior/inferior component, made up of nerve fibers crossing the midline, and an internal anterior/superior component, composed of scantily cellularized and vascularized tissue (Fig. 6C). The posterior commissure was lined by a simple ependymal layer, which did not show any specialization; the subcommissural organ ( $\mathrm{SCO}$ ) was not recognizable in any section. The habenular commissure was also characterized by low cell and microvessel density. Some small calcareous concretions were also visible (Fig. 6D).

\section{Discussion}

The anatomy of the posterior third ventricle has been historically described from a posterior, microsurgical point of view. From this perspective, there are plenty of data deriving from both cadaveric and intraoperative studies. ${ }^{1,5-7}$ Conversely, the anterior, intraventricular face of the posterior wall of the third ventricle has been described mostly in postmortem specimens. ${ }^{5,8,9}$ Neurosurgeons who have approached this area in vivo using an endoscope have done so only to explore or biopsy or remove tumors involving the pineal region. Therefore, only pathological endoscopic anatomy is available for this area. ${ }^{10-23}$

The routine use of a flexible scope in cases of colloid cysts, atresia or neoplastic obstruction of the foramen of Monro, and IVH allows for exploration of the normal anatomy of this difficult-to-access region and its variations. On the other hand, neuroendoscopic procedures for nonneoplastic obstructive hydrocephalus gave us the chance
TABLE 2. Summary of anatomical variations in the posterior third ventricle

\begin{tabular}{lcc}
\hline \multirow{2}{*}{$\begin{array}{c}\text { Anatomical Structure \& } \\
\text { Shape }\end{array}$} & $\begin{array}{c}\text { Nilated Ventricle } \\
(\mathrm{n}=31)\end{array}$ & $\begin{array}{c}\text { Normal Anatomy } \\
(\mathrm{n}=28)\end{array}$ \\
\hline Adytum of the aqueduct & & \\
\hline Triangular & $\mathbf{2 0}(71.4)$ \\
\hline Rounded & $16(51.6)$ & $8(28.6)$ \\
\hline Stenotic & $7(22.5)$ & 0 \\
\hline PC & & \\
\hline Thick & $16(51.6)$ & $27(96.4)$ \\
\hline Thin & $15(48.4)$ & $1(3.6)$ \\
\hline HC & & $19(67.9)$ \\
\hline Thick & $7(22.6)$ & $9(32.1)$ \\
\hline Thin & $24(77.4)$ & \\
\hline HC choroid plexus & & $6(21.4)$ \\
\hline Yes & $17(54.8)$ & $17(60.7)$ \\
\hline No & $14(45.2)$ & $11(39.3)$ \\
\hline Pineal recess & & \\
\hline Wide & $14(45.2)$ & \\
\hline Slit & $17(54.8)$ & \\
\hline
\end{tabular}

Boldface type indicates anatomical features with statistical significance. 


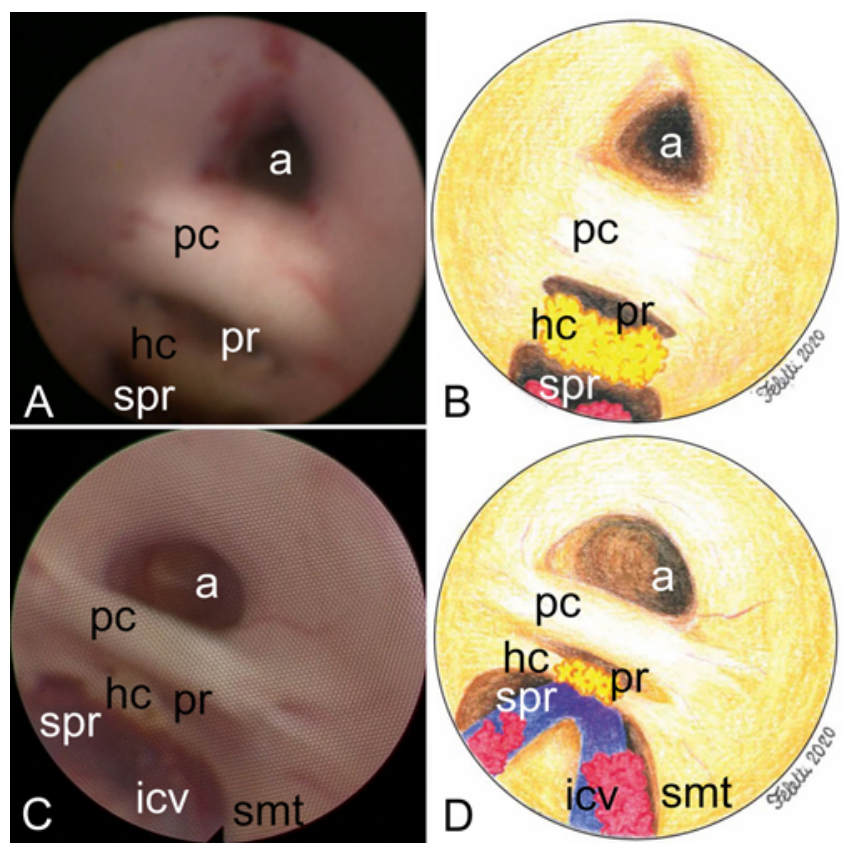

FIG. 3. Comparison between the normal anatomy of the posterior third ventricle $(A$ and $B)$ and the alterations due to chronic hydrocephalus ( $C$ and D). A: The shape of the adytum of the cerebral aqueduct is triangular, and the posterior and habenular commissures appear thicker. B: Artist's illustration showing the normal anatomy. C: The adytum of the cerebral aqueduct is oval, the commissures are thinner, and the pineal recess is also thinner. D: Artist's illustration showing the anatomy in a case of chronic hydrocephalus. a = adytum of the cerebral aqueduct; $\mathrm{hc}=$ habenular commissure; icv = internal cerebral vein; $\mathrm{pc}=$ posterior commissure; $\mathrm{pr}=$ pineal recess; $\mathrm{smt}=$ stria medullaris thalami; $\mathrm{spr}=\mathrm{su}-$ prapineal recess. Copyright Alberto Feletti. Published with permission.

to assess the effects of chronic ventricular dilation on the anatomical structures of the posterior third ventricle.

When approached anteriorly and within the third ventricle, the posterior wall of the third ventricle comprises, from above to below, the suprapineal recess, the habenular commissure, the pineal recess, the posterior commissure, and the adytum of the cerebral aqueduct (Fig. 2). ${ }^{1}$

The suprapineal recess lies below the splenium of the corpus callosum and over the habenular commissure and can always be observed during endoscopic procedures. In nearly half of the cases, the suprapineal recess shows a posterior extension with a membranous structure. This area of the suprapineal recess is surgically relevant, as it has been proposed as an alternative site for third ventriculostomy to divert CSF to the quadrigeminal cistern. ${ }^{24,25}$

The habenula is a paired structure connecting the forebrain to midbrain regions. Its name comes from the Latin habena, meaning "rein." It has a key role in learning and motivation, ${ }^{26}$ in the process of error detection and the ability to adjust accordingly, ${ }^{27}$ and in the perception of pain. ${ }^{28}$ Moreover, it appears to play a role in the pathophysiology of major depression. ${ }^{29}$ It includes 2 subdivisions, lateral and medial, the latter providing projections to the contralateral habenula through the habenular commissure. ${ }^{1,30}$

Along with the pineal gland, posterior commissure, stria medullaris thalami, habenular nuclei, and trigonum habenulae, the habenular commissure is part of the epithalamus.
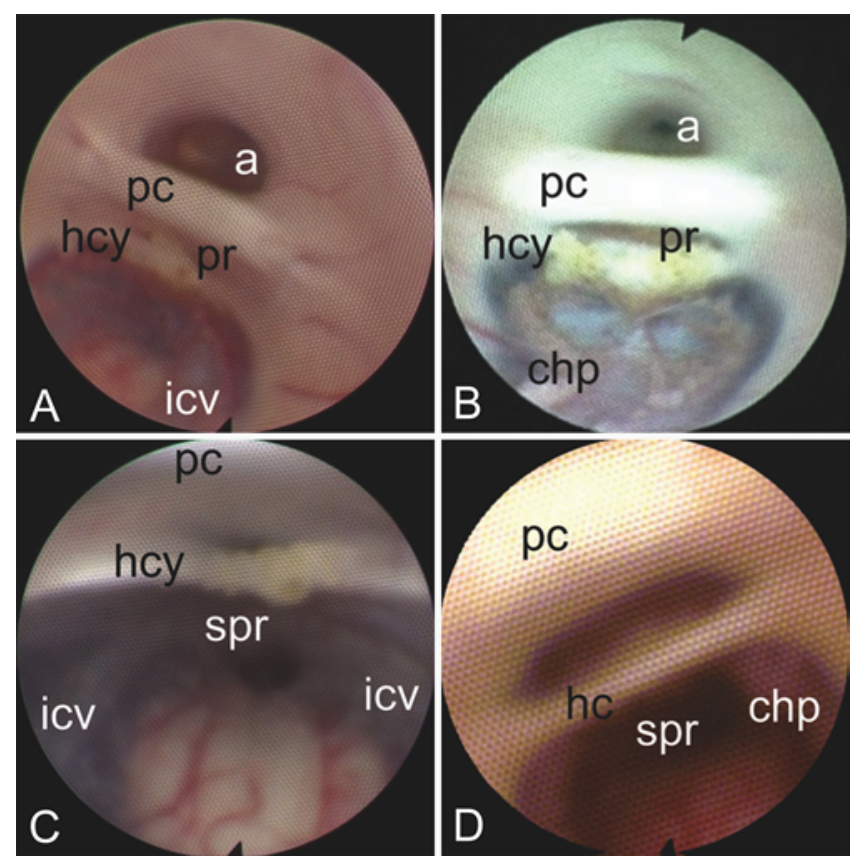

FIG. 4. A-C: Yellowish choroid plexus covering the habenular commissure in most cases. D: When chronic hydrocephalus occurs, the yellowish choroid plexus covering the habenular commissure is less frequently encountered. $\mathrm{a}=$ adytum of the cerebral aqueduct; $c h p=$ choroid plexus; hc = habenular commissure; hcy = habenular commissure covered by yellowish choroid plexus; icv = internal cerebral vein; $p c=$ posterior commissure; spr = suprapineal recess. Copyright Alberto Feletti. Published with permission. Figure is available in color online only.

The habenular commissure connects the bilateral habenular nuclei and is often reported as calcified on plain skull radiographs and CT scans. ${ }^{31}$ Our microscopic studies confirmed that microcalcifications can be present in the context of the habenular commissure. However, based on our findings from direct endoscopic vision, the choroid plexus can also be calcified. The significant similarity of calcification trend by year of life between the habenular commissure and choroid plexus reported by Whitehead et al. supports this hypothesis..$^{32}$ Neurosurgical approaches have shown that the choroid plexus often covers the habenular commissure (81.5\% in normal anatomical cases; Fig. 4). The neuroanatomical study on postmortem samples also confirmed that a separated portion of the choroid plexus might extend inferiorly and posteriorly in front of the habenular commissure. To the best of our knowledge, this is the first description of such choroid plexus covering the habenular commissure. The origin and the eventual function of this choroid plexus are not clear. As the choroid plexus of the third ventricle and the habenular commissure begin their formation at almost the same gestational stage, ${ }^{33,34}$ it is likely that in most embryos some choroid plexus cells lie in the ependymal area that will later form the habenular commissure, giving origin to portions of choroid plexus, which is soon separated from the main choroid plexus of the roof of the third ventricle because of the growing of the habenular commissure. The decrease in vascular supply may therefore induce its atrophy, and this could explain the pale and yellowish appearance of the choroid plexus 


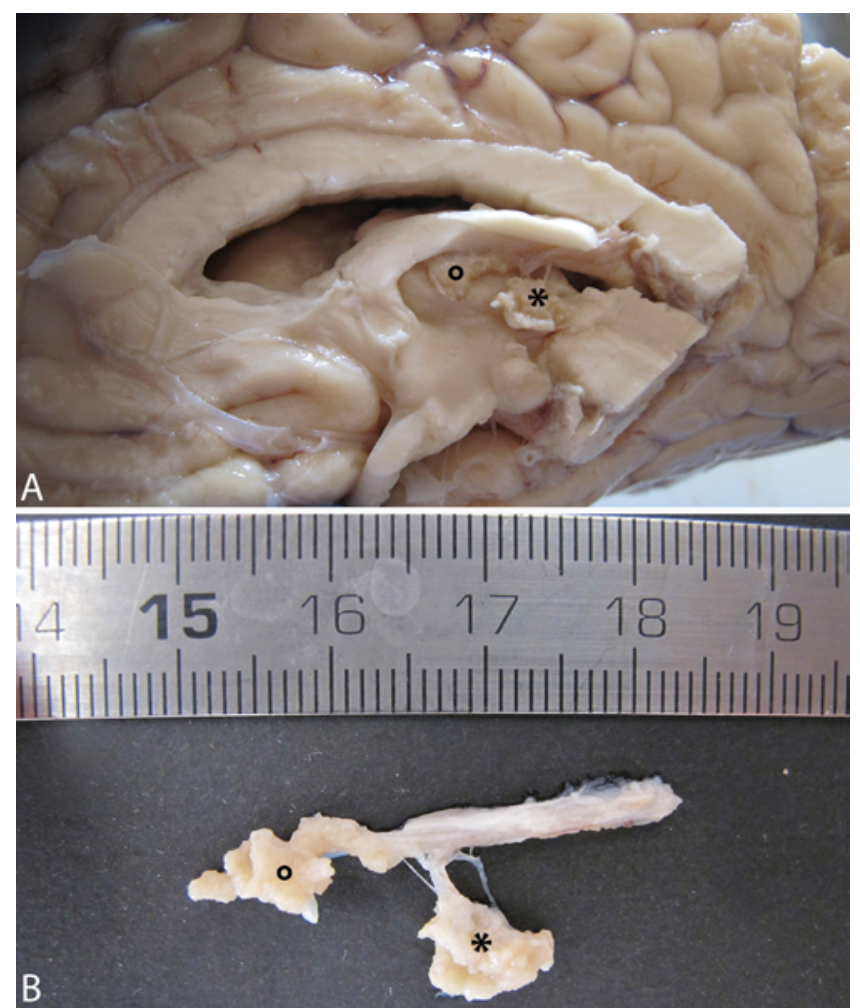

FIG. 5. A: General view of the third ventricle through a sagittal section. Note that the main body of the choroid plexus is located along the ventricle roof $\left({ }^{\circ}\right)$, but a minor portion of the choroid plexus extends posteriorly in front of the habenular commissure $\left(^{*}\right)$. B: Sample of the above choroid plexus showing the clear separation of the portion of the choroid plexus that lies in front of the habenular commissure $\left({ }^{*}\right)$ with respect to the main body of the choroid plexus $\left({ }^{\circ}\right)$. Copyright Alberto Feletti. Published with permission. Figure is available in color online only.

covering the habenular commissure. Interestingly, when chronic hydrocephalus occurs, the choroid plexus covers the habenular commissure in a significantly small number of patients (53.1\% of cases).

In nonhydrocephalic patients, we found a thick habenular commissure in about $70.4 \%$ of cases, while in the presence of hydrocephalus the habenular commissure appeared thin in $78.1 \%$ of cases; this difference was statistically significant. Similarly, the posterior commissure was significantly thicker in nonhydrocephalic patients than in hydrocephalic patients $(96.3 \%$ vs $53.1 \%)$. This can indicate that in case of chronic ventricular dilation, the commissure could be progressively stretched and therefore becomes thinner. Considering the role of the habenular nuclei in learning, motivation, and major depression, it is possible to hypothesize an association between the compromised habenular structures and some symptoms of hydrocephalic patients.

Most of the fibers arriving in the habenular area arise in the nucleus ovalis of the diencephalon and run in the stria medullaris thalami, ${ }^{34}$ which could always be visualized during endoscopic inspections as a paired ridge anterior to the habenular commissure and just below the roof of the third ventricle (Fig. 2).

The pineal gland lies in the quadrigeminal cistern. The

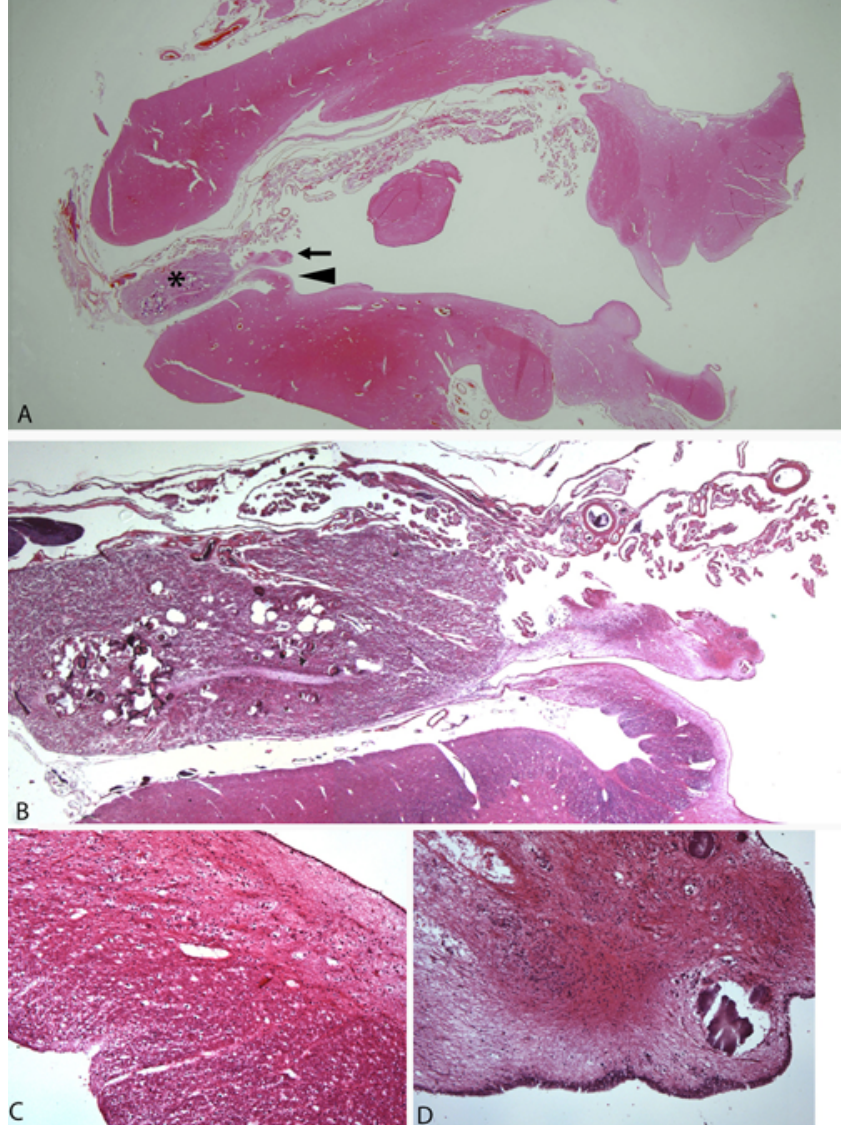

FIG. 6. Photomicrographs. A: Representative sagittal section of the third ventricle, showing the pineal gland $\left({ }^{*}\right)$ and the habenular (arrow) and posterior (arrowhead) commissures on the posterior aspect, together with the extension of the choroid plexus on the ventricular roof. Note that the most posterior part of the choroid plexus is quite near to the habenular commissure. B: Detail of the posterior third ventricle in another section. C and D: Higher magnifications of the posterior and habenular commissures, respectively. $\mathrm{H}$ \& E, original magnification $\times 1.25(\mathrm{~B}) ; \times 10$ $(\mathrm{C}$ and $\mathrm{D})$. Figure is available in color online only.

stalk of the pineal gland divides into a superior and an inferior lamina. While the habenular commissure is located in the superior lamina, the posterior commissure is positioned in the inferior lamina. The pineal recess of the third ventricle, which we were always able to visualize during neuroendoscopic procedures, separates the laminae. In nonhydrocephalic patients, the pineal recess was found to be wide in $63 \%$ of cases, while $56.2 \%$ of hydrocephalic patients showed a thin recess, although this difference was not statistically significant. The pineal gland is considered one of the circumventricular organs, ${ }^{35,36}$ although not all researchers agree that the pineal gland has fenestrated capillaries and lacks a blood-brain barrier. ${ }^{37}$ Consistently with this view, we were never able to detect any fluorescence at the level of the pineal recess after fluorescein sodium intravenous injection (Fig. 2B).

The posterior commissure interconnects the pretectal nuclei, mediating the consensual pupillary light reflex, and has a close relationship with the medial longitudinal fasciculus. ${ }^{38}$ However, after closure of the neural tube, while 
the ventral midline forebrain territories express the diffusible morphogen sonic hedgehog, the dorsal midline forebrain territories express Wnt/BMP, similar to the cerebellar territories. ${ }^{39}$ This developmental link indicates that the posterior commissure might also be associated with posture and the integration of body movements. ${ }^{6}$ Similar to the habenular commissure, the posterior commissure was significantly thicker in nonhydrocephalic patients than in hydrocephalic ones (96\% vs 55\%) (Fig. 3). This suggests that the disequilibrium and balance impairment experienced by patients affected by hydrocephalus might at least partially be correlated with the stretching and mechanical injury of the posterior commissure.

The SCO is a specialized neuroepithelium located underneath the posterior commissure, being the oldest brain gland and the first to differentiate in ontogeny. ${ }^{40}$ Unlike the other circumventricular organs, which have a tight barrier with the CSF and are open to blood, the SCO is closed to both blood and CSF. ${ }^{39,45}$ In humans, different from all other species, the SCO is secretory active only during the fetal period, while after birth it undergoes regressive changes. ${ }^{41,42}$ It is now known that the vascularization of the SCO is almost absent in humans. This can explain why during endoscopic explorations it is not possible to detect it after fluorescein sodium intravenous injection, which is different from what happens with the median eminence on the tuber cinereum and the area postrema on the calamus scriptorius. ${ }^{2,4}$ We were never able to distinctly identify this organ during endoscopic procedures, even after fluorescein sodium intravenous injection. Its identification is problematic in cadaver studies, and it was not identifiable in the postmortem adult samples analyzed in this study. ${ }^{6}$

As already described elsewhere, normally the shape of the adytum of the cerebral aqueduct is triangular. ${ }^{43,44}$ The base of the triangle is outlined by the posterior commissure, and the other 2 sides are delineated by the 2 red nuclei of the midbrain (rubral eminences). In our series, the triangular shape was seen in about $70.4 \%$ of normal cases. Conversely, the shape was rounded or stenotic in chronically dilated third ventricles $(71.9 \%)$.

Our study has some limitations. First, the images obtained with a flexible scope have limited quality, as the instrument is based on fiber optics. Moreover, a precise, direct quantitative measure of anatomical structures is not possible during endoscopic procedures because the apparent sizes change in relation to the distance of the tip of the scope from the structures themselves. Therefore, the features of the adytum of the cerebral aqueduct, the thickness of the posterior and habenular commissures, and the width of the pineal recess were assessed in a qualitative manner, comparing the images taken at approximately the same distance from the tip of the scope.

\section{Conclusions}

Flexible endoscopy allows a thorough and detailed inspection of the least accessible posterior part of the third ventricle. The suprapineal recess, habenular and posterior commissures, pineal recess, stria medullaris thalami, and adytum of the cerebral aqueduct can always be seen. Conversely, the circumventricular organs of this region (pi- neal gland and SCO) are not highlighted by intravenous fluorescein sodium injection. Chronic dilation of the third ventricle alters the anatomy of the commissures, which become thinner, and the shape of the pineal recess, which becomes narrower. These variations may be relevant from a clinical point of view, based on the claimed functions of these structures.

\section{References}

1. Rhoton AL Jr. The lateral and third ventricles. Neurosurgery. 2002;51(4)(suppl):S207-S271.

2. Longatti P, Basaldella L, Sammartino F, et al. Fluoresceinenhanced characterization of additional anatomical landmarks in cerebral ventricular endoscopy. Neurosurgery. 2013;72(5):855-860.

3. Porzionato A, Macchi V, Stecco C, et al. Quality management of Body Donation Program at the University of Padova. Anat Sci Educ. 2012;5(5):264-272.

4. Longatti P, Porzionato A, Basaldella L, et al. The human area postrema: clear-cut silhouette and variations shown in vivo. $J$ Neurosurg. 2015;122(5):989-995.

5. Cavallo LM, Di Somma A, de Notaris M, et al. Extended endoscopic endonasal approach to the third ventricle: multimodal anatomical study with surgical implications. World Neurosurg. 2015;84(2):267-278.

6. Ozdemir NG. The anatomy of the posterior commissure. Turk Neurosurg. 2015;25(6):837-843.

7. Yamamoto I. Pineal region tumor: surgical anatomy and approach. J Neurooncol. 2001;54(3):263-275.

8. Resch KD, Perneczky A, Tschabitscher M, Kindel S. Endoscopic anatomy of the ventricles. Acta Neurochir Suppl. 1994;61:57-61.

9. Riegel T, Hellwig D, Bauer BL, Mennel HD. Endoscopic anatomy of the third ventricle. Acta Neurochir Suppl. 1994;61:54-56.

10. Ahmed AI, Zaben MJ, Mathad NV, Sparrow OC. Endoscopic biopsy and third ventriculostomy for the management of pineal region tumors. World Neurosurg. 2015;83(4):543-547.

11. Chernov MF, Kamikawa S, Yamane F, et al. Neurofiberscopic biopsy of tumors of the pineal region and posterior third ventricle: indications, technique, complications, and results. Neurosurgery. 2006;59(2):267-277.

12. Chibbaro S, Di Rocco F, Makiese O, et al. Neuroendoscopic management of posterior third ventricle and pineal region tumors: technique, limitation, and possible complication avoidance. Neurosurg Rev. 2012;35(3):331-340.

13. Feletti A, Marton E, Fiorindi A, Longatti P. Neuroendoscopic aspiration of tumors in the posterior third ventricle and aqueduct lumen: a technical update. Acta Neurochir (Wien). 2013;155(8):1467-1473.

14. Gangemi M, Maiuri F, Colella G, Buonamassa S. Endoscopic surgery for pineal region tumors. Minim Invasive Neurosurg. 2001;44(2):70-73.

15. Morgenstern PF, Souweidane MM. Pineal region tumors: simultaneous endoscopic third ventriculostomy and tumor biopsy. World Neurosurg. 2013;79(2)(suppl):18.e9-18.e13.

16. Mottolese C, Szathamari A, Beuriat PA, et al. Neuroendoscopy and pineal tumors: a review of the literature and our considerations regarding its utility. Neurochirurgie. 2015;61(23):155-159.

17. O'Brien DF, Hayhurst C, Pizer B, Mallucci CL. Outcomes in patients undergoing single-trajectory endoscopic third ventriculostomy and endoscopic biopsy for midline tumors presenting with obstructive hydrocephalus. J Neurosurg. 2006;105(3)(suppl):219-226.

18. Oi S, Kamio M, Joki T, Abe T. Neuroendoscopic anatomy and surgery in pineal region tumors: role of neuroendoscopic 
procedure in the 'minimally-invasive preferential' management. J Neurooncol. 2001;54(3):277-286.

19. Pettorini BL, Al-Mahfoud R, Jenkinson MD, et al. Surgical pathway and management of pineal region tumours in children. Childs Nerv Syst. 2013;29(3):433-439.

20. Pople IK, Athanasiou TC, Sandeman DR, Coakham HB. The role of endoscopic biopsy and third ventriculostomy in the management of pineal region tumours. Br J Neurosurg. 2001;15(4):305-311.

21. Roth J, Constantini S. Combined rigid and flexible endoscopy for tumors in the posterior third ventricle. J Neurosurg. 2015;122(6):1341-1346.

22. Wellons JC III, Reddy AT, Tubbs RS, et al. Neuroendoscopic findings in patients with intracranial germinomas correlating with diabetes insipidus. J Neurosurg. 2004;100(5)(Suppl Pediatrics):430-436.

23. Wong TT, Chen HH, Liang ML, et al. Neuroendoscopy in the management of pineal tumors. Childs Nerv Syst. 2011;27(6):949-959.

24. Daniel RT, Lee GY, Reilly PL. Suprapineal recess: an alternate site for third ventriculostomy? Case report. J Neurosurg. 2004;101(3):518-520.

25. Idris Z, Johnson JR, Abdullah JM. Endoscopic fenestration at the splenial-habenular junctional area for symptomatic cavum and tumor at the foramen of Monro: case reports and anatomical review. J Neurosurg. 2015;122(3):504-510.

26. Lawson RP, Seymour B, Loh E, et al. The habenula encodes negative motivational value associated with primary punishment in humans. Proc Natl Acad Sci U S A. 2014;111(32):11858-11863.

27. Ide JS, Li CS. Error-related functional connectivity of the habenula in humans. Front Hum Neurosci. 2011;5:25.

28. Shelton L, Pendse G, Maleki N, et al. Mapping pain activation and connectivity of the human habenula. J Neurophysiol. 2012;107(10):2633-2648.

29. Fakhoury M. The habenula in psychiatric disorders: more than three decades of translational investigation. Neurosci Biobehav Rev. 2017;83:721-735.

30. Kim U. Topographic commissural and descending projections of the habenula in the rat. J Comp Neurol. 2009;513(2):173-187.

31. Macpherson P, Matheson MS. Comparison of calcification of pineal, habenular commissure and choroid plexus on plain films and computed tomography. Neuroradiology. 1979;18(2):67-72.

32. Whitehead MT, Oh C, Raju A, Choudhri AF. Physiologic pineal region, choroid plexus, and dural calcifications in the first decade of life. AJNR Am J Neuroradiol. 2015;36(3):575580 .

33. Dziegielewska KM, Ek J, Habgood MD, Saunders NR. Development of the choroid plexus. Microsc Res Tech. 2001;52(1):5-20.

34. O'Rahilly R, Müller F. Ventricular system and choroid plexuses of the human brain during the embryonic period proper. Am J Anat. 1990;189(4):285-302.

35. Horsburgh A, Massoud TF. The circumventricular organs of the brain: conspicuity on clinical 3T MRI and a review of functional anatomy. Surg Radiol Anat. 2013;35(4):343-349.
36. Longatti P, Perin A, Rizzo V, et al. Ventricular cerebrospinal fluid melatonin concentrations investigated with an endoscopic technique. J Pineal Res. 2007;42(2):113-118.

37. Duvernoy HM, Risold PY. The circumventricular organs: an atlas of comparative anatomy and vascularization. Brain Res Brain Res Rev. 2007;56(1):119-147.

38. Lavrador JP, Ferreira V, Lourenço M, et al. White-matter commissures: a clinically focused anatomical review. Surg Radiol Anat. 2019;41(6):613-624.

39. Suárez R, Gobius I, Richards LJ. Evolution and development of interhemispheric connections in the vertebrate forebrain. Front Hum Neurosci. 2014;8:497.

40. Schoebitz K, Garrido O, Heinrichs M, et al. Ontogenetical development of the chick and duck subcommissural organ. An immunocy tochemical study. Histochemistry. 1986;84(1):31-40.

41. Galarza M. Evidence of the subcommissural organ in humans and its association with hydrocephalus. Neurosurg Rev. 2002;25(4):205-215.

42. Oksche A. The subcommissural organ. J Neurovisc Relat. 1969;31(suppl 9):111.

43. Longatti P, Fiorindi A, Feletti A, et al. Endoscopic anatomy of the fourth ventricle. J Neurosurg. 2008;109(3):530-535.

44. Longatti P, Fiorindi A, Perin A, Martinuzzi A. Endoscopic anatomy of the cerebral aqueduct. Neurosurgery. 2007;61(3) (suppl):1-6.

45. Rodríguez EM, Oksche A, Hein S, Yulis CR. Cell biology of the subcommissural organ. Int Rev Cytol. 1992;135:39-121.

\section{Disclosures}

The authors report no conflict of interest concerning the materials or methods used in this study or the findings specified in this paper.

\section{Author Contributions}

Conception and design: Feletti. Acquisition of data: Feletti, Fiorindi, Lavecchia, Porzionato. Analysis and interpretation of data: Feletti, Fiorindi, Lavecchia, Boscolo-Berto, Marton, Macchi. Drafting the article: Feletti, Lavecchia. Critically revising the article: Feletti, Fiorindi, Marton, Macchi, De Caro, Longatti, Pavesi. Reviewed submitted version of manuscript: all authors. Approved the final version of the manuscript on behalf of all authors: Feletti. Statistical analysis: Lavecchia, Boscolo-Berto. Study supervision: Feletti, De Caro, Longatti, Porzionato, Pavesi.

\section{Supplemental Information \\ Videos}

Video 1. https://vimeo.com/410331787.

Video 2. https://vimeo.com/410331845.

\section{Correspondence}

Alberto Feletti: University of Verona, Italy. alberto.feletti@univr.it 